\title{
Every Drop of Water Footprint Counts For Humanity
}

\author{
Liew Kian Heng ${ }^{1 *}$ and Liew Yuqiang ${ }^{2}$
}

${ }^{1}$ LiEW STRATEGiCS, 25 Bukit Batok Crescent, 04-04 Singapore 658066

${ }^{2}$ LiEW ENZYMiCS, 123 Bukit Merah Lane 1, 04-118, Singapore 150123

\begin{abstract}
Since 2002, Water Footprint concept was developed by Hoekstra as an indicator of water use behind all the goods and services consumed by one individual or the individuals of a country, more new concepts and definition evolved to 'The water footprint is a measure of humanity's appropriation of fresh water in volumes of water consumed and/or polluted'. Water Footprint answers how earth's limited freshwater resources are being consumed or wasted through pollution or by misuse, abuse and disuse. At the highest level of United Nations, there are Sustainable Development Goals 2030 to achieve development programmes such as 'Leaving No One Behind'. From nations to corporations, reduce Water Footprint contributes to sustainability and in shrinking the Carbon Footprint to conserve energy with less wastages, less wastefulness at all levels. Less Water Footprint, Less Carbon Footprint and Less Global Warming. Every individual as a stakeholder can realise and practise stringently the concept of Every Drop Counts. Developed countries like Singapore consumed more water and yet with widespread education, study found that 'Saving water less of a concern for younger residents'. The author and co-author provide mentorship/internship to Universities and Polytechnic to learn 'Every drop Counts' from concept of Water Footprint. The mentees/interns were driven on learning by listening and undertaking hands-on-real-life measuring individual Water Footprint at their 3-month internship venue called The Living Lab. They collected and used every drop of water drips from the taps in the Living Lab to imbue the true meaning of Every Drop Counts for life-long. Every individual, home, corporation as well as every country when practises water-saving for proper use contribute to humanity. The youngsters and the educated must listen, learn, contribute and secure mother earth's environment.
\end{abstract}

\section{Introduction}

The poem, [1] Rhyme of the Ancient Mariner has this part stanza,

Water, water, every where,

And all the boards did shrink;

Water, water, every where,

Nor any drop to drink.

* Corresponding author: liew@strategics.com.sg 
was famously written by Samuel Taylor Coleridge in 1797. After more than 200 years in the history and culture of humanity, the story on availability and security of water to drink has even become more relevant to mankind. Since then the literacy as well as level of education around the world have increased and multiplied with science and technological knowledge surging into forefront space age researches on water. With improved economies and technologies to source, extract, process, transport and store high quality of potable water, the question of "nor any drop to drink" should be a shrink. However, the whole world is at the brink of water crises in many countries with compounded growing epidemics and calamities due to climate change and global warming. The facts on clean water today in the $21^{*}$ century is alarming on the security of humanity.

From [2] WHO lives website it shows that the scarcity of clean and safe potable water are glaring:

2.1 billion people globally do not have access to clean, safe drinking water.

3.4 million people die each year from scarce and contaminated water sources.

Millions of women and children spend 3-6 hours each day collecting water from distant and polluted sources.

The time it takes to walk the average 3.7 miles for clean water is time not spent generating income, caring for family members, or attending school.

At any given time, half of the world's hospital beds are occupied by patients suffering from diseases associated with lack of access to clean water.

In accordance to the United Nations, on [3] "The Right to Water", it stated:

One of the most important recent milestones has been the recognition in July 2010 by the United Nations General Assembly of the human right to water and sanitation. The Assembly recognized the right of every human being to have access to enough water for personal and domestic uses, meaning between 50 and 100 litres of water per person per day. The water must be safe, acceptable and affordable. The water costs should not exceed 3 per cent of household income. Moreover, the water source has to be within 1,000 metres of the home and collection time should not exceed 30 minutes.

Indeed, $70 \%$ of the earth's surface is covered with water. Only $1 \%$ of the water is fresh water available for abstractions for direct human consumption. As the world's population is predicted to increase from about 7 to 11 billion by 2100 , the pressure on potable water will be also a human equality, equity as well as security problem. The problems will be multiplied many folds due to incessant environmental disasters, partly is man-made and coupled grossly with greed-derived contamination catastrophes. Water shortage problems will be compounded to other related health, hygiene, infections and livelihood problems with associated attrocities particularly in less developed nations.

Yet with so much ability to treat and produce good drinking water one third of the world is still suffering from proper access while millions are consuming daily deadly contaminated water nor any drop to drink. At the same time, those who are more educated hence more economically developed have direct access daily with running tap water till their brink with no shrink to their Water Footprint unabatedly. 


\section{Education, Economy, Population and Water}

\subsection{Education}

Over the last 200 years the educational standards and hence economic prosperities of many countries in particular the OECD, have risen with increasing consumption of goods and services. From [4] Our World in Data, the world literacy rate which is a measure of education level has rapidly increased with doubling the global average from 1960 to 2010 in 50 years. This represented about $4 \%$ increase per year over the 50 years period.

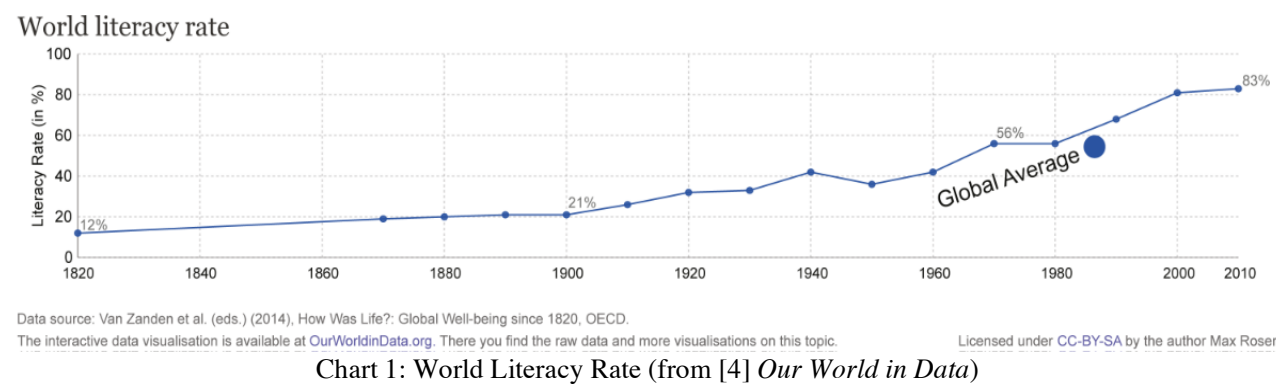

Literacy is a basic key skill to acquire other cognitive and vocational skills. From the paper on [5] Role of Education Quality in Economic Growth by Eric A. Hanushek and Ludger Wößmann, it explained that the simple answers in the discussion of economic implications of education are that educational quality, measured by cognitive skills, has a strong impact on individual earnings. More than that, however, educational quality has a strong and robust influence on economic growth.

\subsection{Economy}

With increase in education the economic prosperities come in tandem as measured by the growth in per capita GDP. This can be seen by the rapidly rise similar to the trend in education from 1960 to 2016 with more than doubling in the per capita GDP. East Asia was increasing from $\$ 2,000$ to $\$ 10,000$ while Western Europe was from $\$ 10,000$ to $\$ 40,000$. These were 5 and 4 folds increases respectively. The world saw an increase from $\$ 4,000$ in 1960 to about $\$ 14,000$ in 2016 . This is about $350 \%$ increase in per capita GDP representing a $6.2 \%$ growth per year.

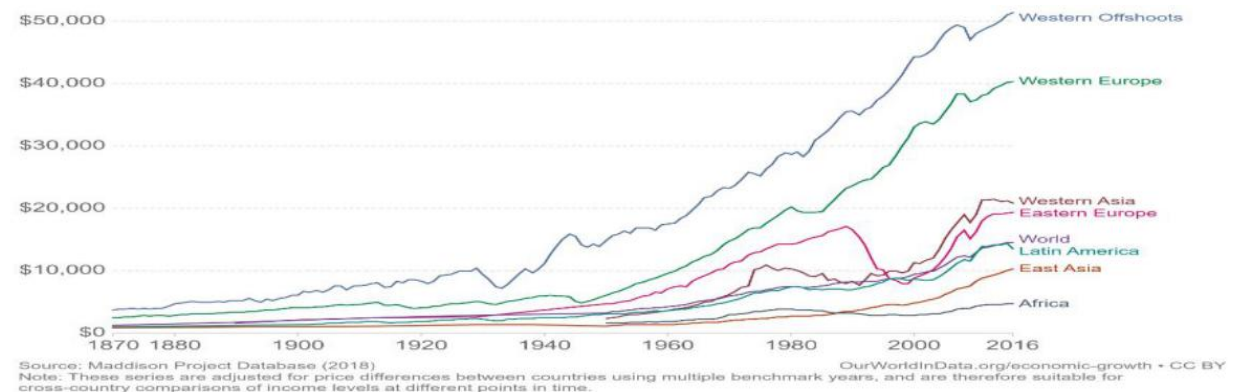

Chart 2: World GDP per Capita (from Our World in Data) 


\subsection{Population}

From Our World in Data, the population of the world was estimated to be 3.03 billion in 1960 and grew into 6.96 billion in 2010, 7.38 billion in 2014 and then 7.47 billion in 2016 . It grew double from 1960 to 2010 by 3.66 billion representing 0.073 billion a year. Today we have 7.80 billion people on this planet earth. From 1960, the annual increase is 0.0795 billion a year representing a $4.3 \%$ annual growth.

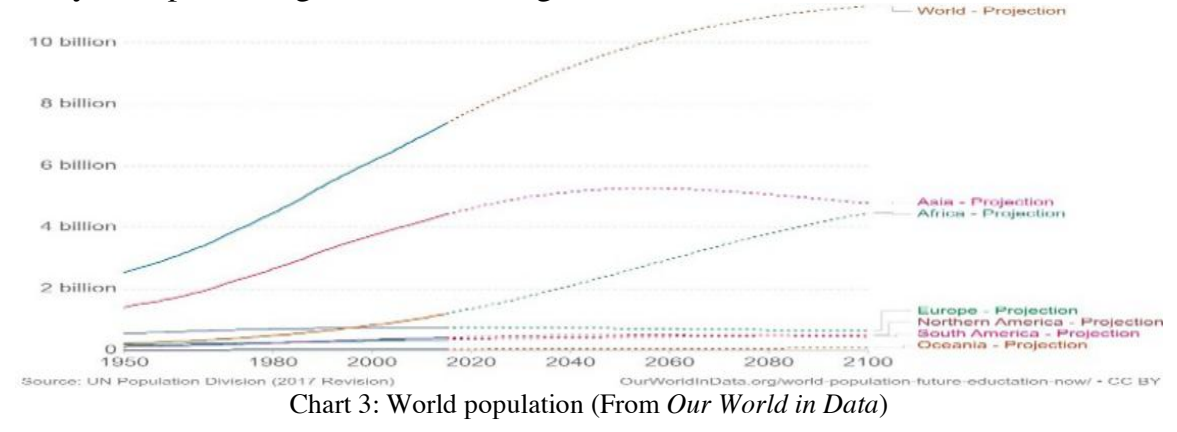

\subsection{Water}

With increasing per capita GDP the corresponding rise in the consumption of water for agriculture, industries and domestic use also coincided with the rapid 50-year trend from 1960 to 2014. The increase is similar to the doubling of literacy rate with almost proportionally doubling the global water consumption.

In 1960 the world consumed about 1.75 trillion $\mathrm{m} 3$ and escalated to 4 trillion $\mathrm{m} 3$ in 2014 . This is $229 \%$ increase over 54 years representing $4.2 \%$ rate of increase every year.

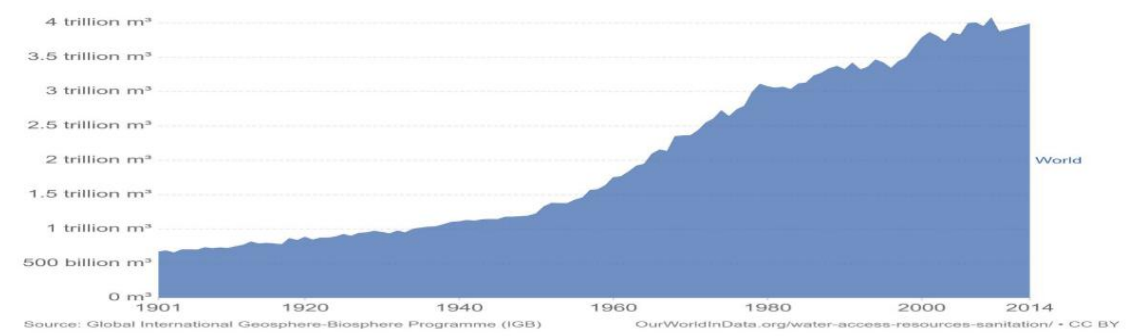

Chart 4: World water use (From Our World in Data)

\section{Water Footprint and Virtual Water}

For a country, the Water Footprint is broadly for measuring the country's fresh water used for the population's consumption and/or resulted in contamination. The concept can similarly be applied further to smaller scale for instance to a province, a city, a corporation, an institution, a family or home, a product and an individual. The concept helps to focus on the dependence, policy, management, regulation, security as well as any other broader issues such as on where and when water resources are taken care for the country.

A country's Water Footprint not only takes into account of water resources such as rainwater from water bodies and ground water use physically, there is also water use in producing imported products by other countries as well as water use for producing exported products by the country. The aggregate of all these water uses captures the nations' Water Footprint. Similarly, one can account for the smaller scale entities right down to an individual's Water Footprint. 


\subsection{Meaning of Water Footprint}

Professor Arjen Y. Hoekstra in September 2002 first introduced the concept of "water footprint" in the report:

[6]Virtual water trade

A quantification of virtual water flows between nations in relation to international crop trade:

For each nation of the world a 'water footprint' has been calculated (a term chosen on the analogy of the 'ecological footprint'). The water footprint, equal to the sum of the domestic water use and net virtual water import, is proposed here as a measure of a nation's actual appropriation of the global water resources. It gives a more complete picture than if one looks at domestic water use only, as is being done until date. In addition to the water footprint, indicators are proposed for a nation's 'water self-sufficiency' and a nation's 'water dependency'.

Water Footprint gives a link between human consumption and the appropriation of the entity's freshwater resources. There are three components in this measurement of humans' appropriation of freshwater resources by way of colour - blue, green and grey.

The blue Water Footprint is the consumption of blue water resources (surface runoff and below ground water). It is the consumed volume of freshwater that is incorporated into a product or evaporated as a result of production. Blue Water Footprint is in all sectors such as from industry, agriculture to domestic use.

The green Water Footprint is the consumption of green water resources i,e rainwater . It is the consumed volume of freshwater that is incorporated into plants or evaporated. Green Water Footprint is mainly in plantations, forestry and agri-horticultural uses.

The grey Water Footprint is the consumption of freshwater required to assimilate pollutants to achieve certain standards of water quality. It is the consumed volume of freshwater to dilute the pollutant load so as to maintain the quality standards. The grey Water Footprint is related to the pollution discharged by way of leaks, leaches, runoff etc to a freshwater resource.

\subsection{Meaning of Virtual Water}

In February 2003, AY Hoeskra and PQ Hung in their report: [7] Virtual water trade Proceedings of the International Expert Meeting on Virtual Water Trade explained that :

The concept of 'virtual water' has been introduced by Tony Allan in the early nineties (Allan, 1993; 1994). It took nearly a decade to get global recognition of the importance of the concept for achieving regional and global water security.

After about a quarter of century, this concept of Virtual Water is gathering more recognition and attention. Unlike the every physical drop of water we see, this "virtual water" is invisibly embedded or embodied or entrenched in all the products we consumed from food eaten to the foot wear we use; anything we can see and touched in our daily lives for comfort, standard and security.

[8] Definition of 'virtual water' Virtual water is the water 'embodied' in a product, not in real sense, but in virtual sense. It refers to the water needed for the production of the product. Virtual water has also been called 'embedded water' or 'exogenous water', the latter referring to the fact that import of virtual water into a country means using water that is exogenous to the importing country. Exogenous water is thus to be added to a country's 'indigenous water' (Haddadin, 2003).

The Water Footprint of a product (alternatively known as "virtual water content") expressed in water volume per unit of product (usually m3 ton-1) is the sum of the Water Footprints of the process steps taken to produce the product. 


\subsection{Multi-Dimensional Indicator}

The internal Water Footprint of a nation is the volume of water used from domestic water resources to produce the goods and services consumed by the population of the country. The external Water Footprint of a country is the volume of water used in other countries to produce goods and services imported and consumed by the population of the country. Water Footprint of a nation (or any other entity) at a particular time is henceforth depending on the educational level, economic development and population size.

From the above understandings (blue, green, gray, virtual, direct, indirect, embedded, exogeneous, indigeneous etc), Water Footprint is indeed a multi-dimensional indicator of volumetric water use and pollution of an entity with a certain time as well as location relationships.

\subsection{Water Footprint Sustainability}

John Anthony Allan who invented the concept of Virtual Water in 1993 argued that water should be seen as liquid capital. He highlighted in his book, [9] Virtual Water : Tackling the Threat to our Planet's Most Precious Resource :

At a time when the world's resources are being used up at increasingly alarming rates what can we do to help tackle the threat to our planet's most precious resource? ...... he exposes the real impact of our modern lifestyle and shows how we as individuals, and governments globally, can make a vital contribution to managing our water use in a more sustainable and planet-friendly way.

It is for us who are educated and still living on this planet right now that everyone has a moral duty first not affluently create more effluent in mother-earth loving sustainable way. Every individual must listen to learn how to shrink one's water footprint and embrace the concept to the brink on nor a drop to drink till every drop counts.

\section{Wastages And Wastefulness}

For sustainability starting at an individual level, the daily lifestyle volume of visible water wastages footprint is wastefulness. At every turn of the tap, fresh clean potable water is wasted more than the real use needs. The insatiable wants and recalcitrant habits of economically developed modern societies at every level of a country has the trappings of wastefulness straight from the tap.

\subsection{Sustainable Way}

To educate and understand how freshwater should not be wasted so as to reinforce the sustainability of Water Footprint, every individual shall make nor a drop to drink till every drop counts their mantra by recognising all the ways water are to be cared for :

\subsubsection{Use of Water}

Already in a year the world consumes 4 trillion $\mathrm{m} 3$ of water. A world citizen needs on average of 5 litres of water to drink every day. Citing [3] United Nation's "The Right to Water" the efficient and adequate use should be 50 and 100 litres of water per person per day. This includes the use of water to drink, food preparation, shower, ablution, wash clothes etc as in domestic use. From [10] The World Counts, an average American citizen uses 100 to 175 gallons of water per day. ( 1 US gallon $=3.7854$ litre) This is 6.6 to 7.6 to times of an average world citizen domestically consumes in a day. 
In addition, The world Counts stated that: Agriculture alone can consume 75 to $90 \%$ of a region's available freshwater. Did you know that 1 ton of grain requires 1000 tons of water? The steak you eat requires 1,232 gallons. I bet that never crossed your mind...

In USA alone, [12] Wikipedia data shows a $477 \mathrm{~km} 3$ of water withdrawal in year 2000 with a per capita water consumption of $1600 \mathrm{~m} 3 /$ year/person.

\subsubsection{Misuse of Water}

Clean fresh drinkable water straight from the tap is often not efficiently and appropriately used for the particular purpose on preciously for drinking, food and hygienic livelihood use. Misuse comes in the form of uncontrolled watering lawns and landscape plants, car washing, bathtub bathing, laundry and kitchen wash etc indiscriminately. These are related to excessive and ineffective use resulting in wastages. Some form of substitute such as rainwater harvesting or multiple uses or manual washing rather than hosing down of potable water could abate misuse.

\subsubsection{Abuse of Water}

Good clean water is conveyed by pipes and such system intrinsically have leaks at joints and due to wear and tear. Without timely fixing leakages by huge water guzzlers like in USA, a $1 \%$ of water wastages can amount to $4.77 \mathrm{~km} 3$ (47.7 million $\mathrm{m} 3$ ) of water abuse based on year 2000 figure.

[13]From Global Citizen website, it stated that: In 2015, the Environmental Protection Agency released a report as part of Fix A Leak Week that detailed the 1 trillion gallons of household water trickling through faulty faucets, punctured pipes, or perpetually running toilets every year in the US.

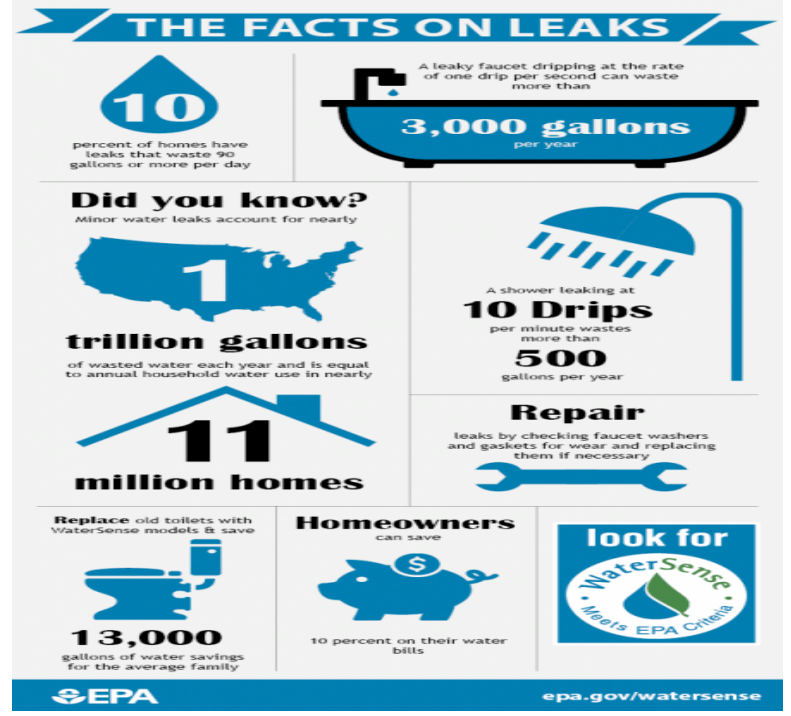

Figure 1. From [14] EPA WaterSense

There are other forms of abuse of water sources by way of pollution diffuse and refuse contaminations from pharmaceuticals, chemicals, fertilisers, toxic disposals, farm waste leaching etc that are destroying aqua lives and promoting other forms of biological growth such as algae blooms to water courses. Such water bodies could become of disuse for agriculture or human consumption. 


\subsection{Affluent Vs Effluent}

Over the years, different countries developed differently with differing growth rates. The four diverse countries identified below have different education, economic, demographic and water consumption patterns.

Table 1. Country comparison

\begin{tabular}{|lcccc|}
\hline $\begin{array}{l}\text { Country } \\
\text { Water } @\end{array}$ & & Literacy Rate* & Per Capita GDP*\# & Per Capita \\
\hline USA & $99+$ & 49,267 & 1600 \\
\hline China & & 95 & 9,475 & 415 \\
\hline Indonesia & 93 & 7,378 & 372 \\
\hline Singapore & 96 & 61,827 & $60^{\wedge}$ \\
\hline
\end{tabular}

Notes : The data are sourced from various websites (see [12] \& other References) to give a trend and not comparing yoy or yty basis.

+ Extrapolated * In 2010 \#USD @ @m3/year in year 2000^ no data in most websites except from PUB website for household use in 2000 calculated at 165/1/persons/day

From above section, Agriculture alone can consume 75 to $90 \%$ of a region's available freshwater. Unlike Singapore, USA, China and Indonesia are huge agriculture countries. The balance of 25 to $10 \%$ of per capita water for non-agricultural use could be accounted partly towards household or domestic use. Then the household per capita could be estimated to be between:

$$
\begin{aligned}
& \mathrm{USA}=160 \text { to } 400 \mathrm{~m} 3 / \text { year } \\
& \text { China }=41.5 \text { to } 103.8 \mathrm{~m} 3 / \text { year } \\
& \text { Indonesia }=37.2 \text { to } 93 \mathrm{~m} 3 / \text { year }
\end{aligned}
$$

USA is the largest economy and most affluent while China is the most populous. China is 4 times more populous but only used one quarter of USA's per capita water consumption. The amount of freshwater wasted by USA in a year is 1 trillion gallons ( 1 gallon $=3.78541$ litre) which is 3,785 million $\mathrm{m} 3$.

Singapore is considered the smallest in population size but high in literacy rate and per capita GDP. For a population of about 5.5 million, the amount of water used at $60 \mathrm{~m} 3 /$ year/person amounts to 330 million m3/year. One year of household wastefulness in USA is more than 11 years of Singapore's household water consumption.

In contrast, Indonesia is using a quarter of USA per capita water consumption. Being a fourth most populous developing country in the world, Indonesia's Water Footprint is promising and exemplary for the rest of the world to emulate. Basing on United Nation's consumption of 50 and 100 litres of water per person per day, Indonesia is performing much better than Singapore and comparatively lower than China.

The more affluent countries with higher education and economic wealth, the more water is used. Consequently, more water is wasted by virtue of use, misuse and abuse directly or indirectly. Affluent countries are needlessly creating more effluent hence wastefulness. Are all the education on sustainability, conservation and green to save mother earth really taking roots from the lowest individual level to the highest entity? Are our children learning enough or given a chance to be imbued on nor a drop to drink till every drop counts?

\section{Listen to Learn}

Our institutions of education as well as every entity together with the leaderships shall take full cognizant of wastefulness at every level. Are we really listening and are we learning 
about the sanctity and value of liquid capital seriously? In saving water at the source at every level, we are cutting down the Water Footprint instantly. This further also is compounded into reducing energy as well as the Carbon Footprint associated in the treatment as well as production of physical and virtual water. This results in multiple cost savings.

Learning to save for sustainability starts with [15] Minimum Level of Learning in listening with care in the trifecta of guidance, compliance and obedience. Every country has their listening message to their citizens to create a listening conversation society to learn on saving precious water. In USA, the Environment Protection Agency's WaterSense (Leaks Can Run, but They Can't Hide) and Singapore's National Water Agency, Public Utilities Board (PUB) (Make Every Drop Count) are encouraging to educate all especially the young.

But real listening as in the ancient Chinese way of “聽” (ting) is with the "耳" (ear), "十" (ten), "目" (eye), with "一" (one) and "心" (heart) as in making of an "王" (emperor) in real learning.

So a student in real life learning on Water Footprint sustainability shall use all the faculties (ears, eyes, heart) to rationalise the sanctity and value of liquid capital. Water is life and every drip and drop is precious for life. There must be a full-one-heart ("十", "一", "心") commitment to be a "王" in eradicating wastefulness.

How can we make every individual realise the drip and drop of every leak can be saved from wasting off as effluent?

This lesson can be learnt in anywhere and those mentees who are from universities and polytechnics attached to the author's organisation have to undergo a program called "Water Footprint- Every Drop Counts". Mentees having good listening intent throughout the program are also imbued with guidance, compliance and obedience in the care of water for life.

\section{The Living Lab}

In this venue of mentorship, 3 participating mentees (one from National University of Singapore and 2 from Singapore Polytechnics) were learning in a Living Lab where each and every one was taking part and be a part of the experiment. The objectives of undertaking this program were as follows:

a. Understanding water footprint at individual level,

b. Creating every drip and drop counts mind set,

c. Applying Water Footprint sustainability,

d. Realising the national water agency's aim of 130 1/person/day by 2030 .

\subsection{Water Drip Sources}

Only three sources of water were made available in the Living Lab for daily use. One was at the wash basin tap (collecting drinking water) and the 2 other at bathroom taps (collecting all-other uses of water). All other tap sources of water were turned and sealed off. The WC serving the flush system (which accounts for a huge part of water usage in most homes) was also turned off.

The 3 participating mentees simulated common water leaks in pipes by adjusting the 3 taps till there were drips at a suitably slow rate. Each mentee was responsible for each tap hence Water Footprint. The drips from these 3 experimenting tap sources were to fill up 3 separate plastic containers. Collection of these 3 sources of water was on-going daily 24/7 non-stop even over week ends. The main water meter reading was recorded at the start and continue recording daily. All the water collected were for immediate daily use in the Living $L a b$ and any excess were also stored for further use. 


\subsection{Measuring and Monitoring}

Measuring of water collected in the containers were made every morning.

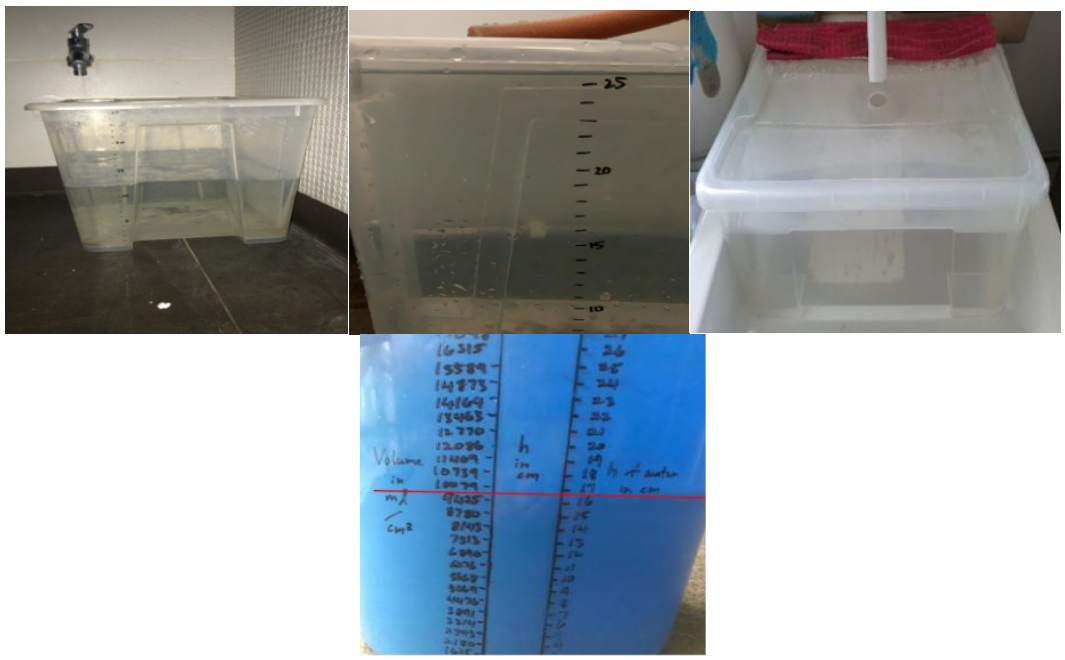

Picture 1: Collection of water drips in transparent containers in bathroom and wash basin. Water was measured in the blue measuring container.

\subsection{Water Use}

The water collected every day was used for drinking (from drinking container) by filling up the 1.7 litres pot for boiling. The 2 (all-other uses) containers of water were used for aquarium water, algae propagation in aquarium and algae hanging bags. The water for watering potted plants was recycled from the waste water taken out of the aquarium.

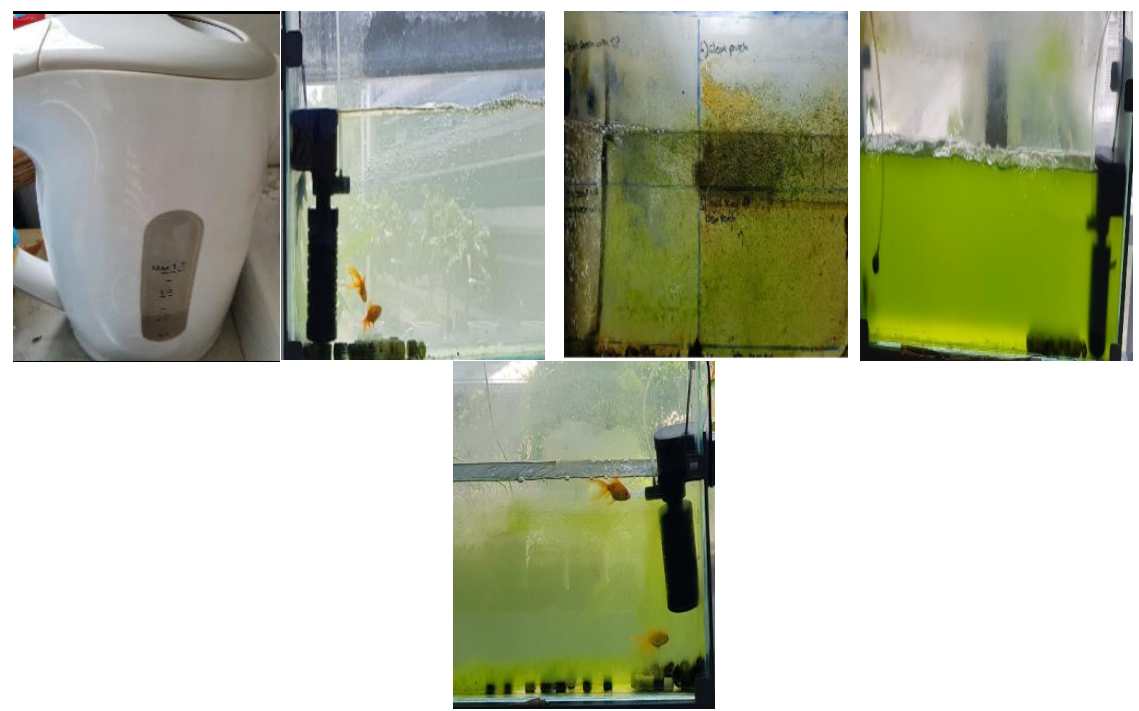

Picture 2: Water use by 1.7 litre pot, 8 similar fish and algae propagation aquaria. 

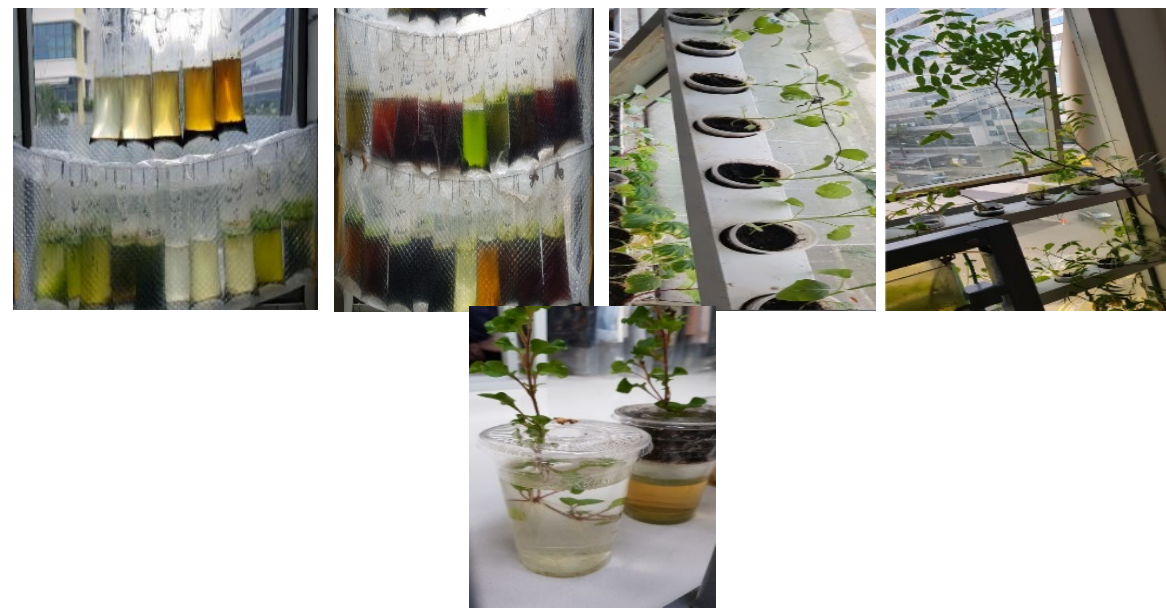

Picture 3: Algae propagation hanging bags, potted plants of vegetable and aquatic species.

In addition, the mentees also used the collected water for toilets, washing and cleaning purposes. Initially, the Living Lab water meter was not registering at all the drip water collected for a few months. PUB discovered and presumed the meter was faulty and then changed a new meter. The replaced meter too did not register the actual volume of water collected in subsequent months too.

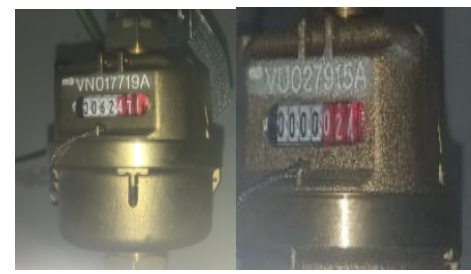

Picture 4: Old and replaced water meter

\section{Every Drop Counts Results}

The water measurement was made by calculating the volume of water filled in the containers every morning. Since the containers were of trapezoidal shape, the calculated volume collected were further verified by pouring into the blue bucket. The collected volumes over the 4 months are as follows:

Table 2. Water collection records

\begin{tabular}{|l|l|l|l|l|}
\hline Month & $\begin{array}{l}\text { Volume } \\
\text { Collected }(\mathrm{l})\end{array}$ & $\begin{array}{l}\text { Drip Rate } \\
(\mathrm{ml} / \mathrm{min})\end{array}$ & $\begin{array}{l}\text { Meter } \\
\text { Reading (l) }\end{array}$ & Remarks \\
\hline 3-31 May 19 & 225.00 & $3.9-22.5$ & 0 & 4 Sundays \\
\hline 3-27 June 19 & 297.91 & $5.58-13.3$ & 0 & 4 Sundays \\
\hline 1-29 July 19 & 268.20 & $4.0-13.6$ & 16 & 4 Sundays \\
\hline
\end{tabular}




\begin{tabular}{|l|l|l|l|l|}
\hline 1-24 August 19 & 178.19 & $4.54-10.3$ & 5 & 3 Sundays \\
\hline
\end{tabular}

The total number of days water was collected $=29+25+29+24=107$ days

Total volume of water collected over 4 months $=221.00+297.91+268.20+278.19=969.3$ litres

Number of mentees during 4 months $=3$

Number of working days $=107-15=92$ days

Water Footprint $=969.3 / 3 / 92=3.512$ litres $/$ person $/$ day

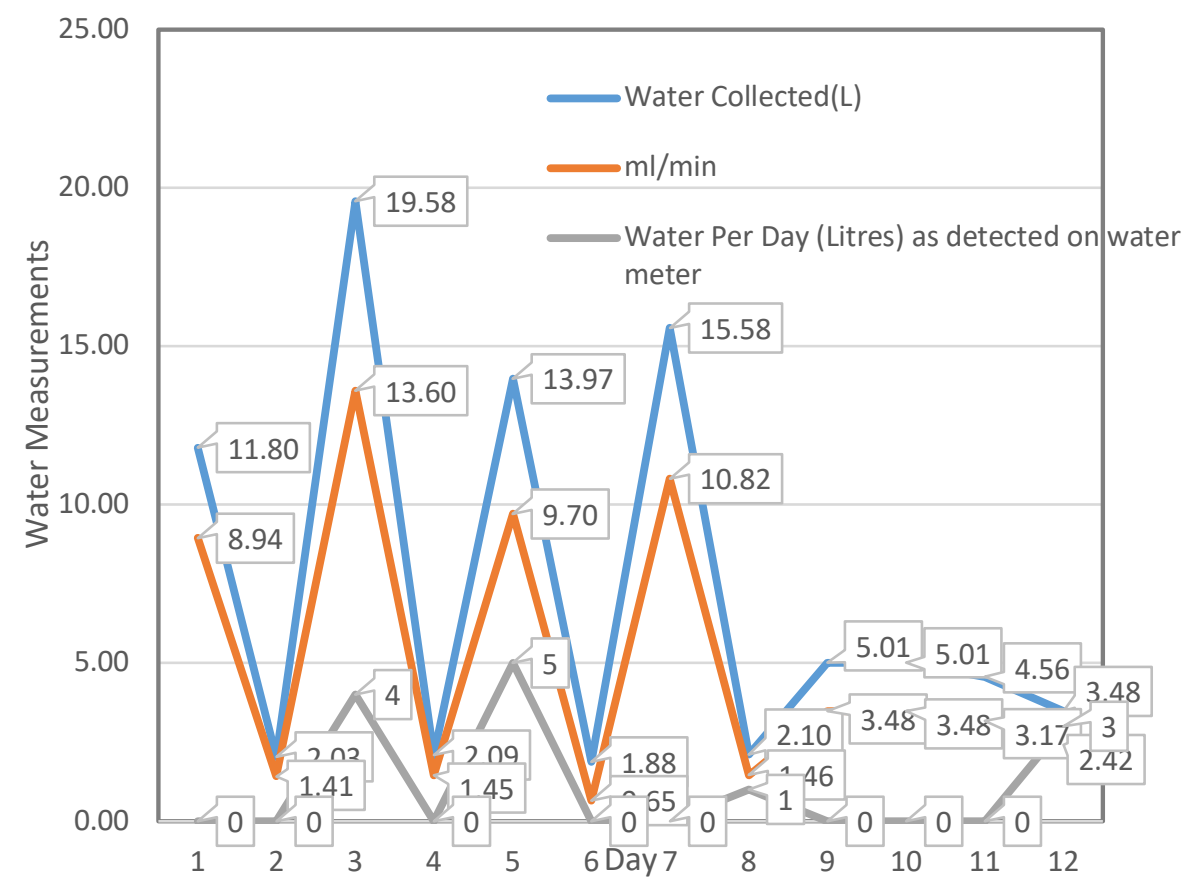

Chart 5: A typical plot of water recordings for partial month of July

\section{The Water Footprint Lesson}

The educational and economic advancements in last 60 years have accelerated the consumption of depleting resources while the understanding of liquid capital value is still not fully appreciated with unabated wastefulness. The concerns have been highlighted at national levels and in Singapore many campaigns and messages have been spread on every drop counts:

[16] We bet, like, $80 \%$ of Singaporeans waste water like this

You may not realise it, but these are the things you do everyday that contribute the most to your water bill.

[17] The Big Read: To build a strong water-saving culture, S'pore needs more than recycled messages

[18] Are You Wasting Water?

[19] Saving water less of a concern for younger residents: Study

[20] Environment And Sustainability. Why water conservation efforts often come up dry 
The Living Lab has given the opportunity for real listening in learning by applying every drip and drop that can be collected for proper daily use. The 3 mentees realised that Water Footprint of each individual can be consciously established and adopted once there was guidance, compliance and obedience mind set. The Water Footprint sustainability involves proper use to cut down abuse and misuse by recycling waste water from the aquaria for watering plants without any effluent generated. The Water Footprint realised was 3.512 litres/person/day working in the Living Lab. The individual personal use of water for drinking, flushing of toilet, hand washing and cleaning (bathing, laundry etc were all home based) were all conservative and minimised. Comparing with the 2030 target of 130 litres/person/day set by Singapore, the 3.512 litres/person/day use during working hours was shown to be achievable. The lesson learnt could also be expanded into other ways of reducing Water Footprint.

Singapore could adopt harvesting the incessant rainwater for direct use in toilets of high rise multi-storey homes. Collection could be done at the roof top and allowed to drain down by gravity directly to fill up the WC in each apartment without any cross contamination with potable pressured water. In addition towards zero wastefulness, tap water that gushes out and drained away instantly could be first trapped at every turn of the tap. This tap water trap allows water to be accumulated and then be released for proper and efficient use instead of becoming effluent straight into the floor trap.

\section{Conclusion}

This paper has uncovered higher education and economic development create more wastefulness and it established the need for all to consciously control and reduce the Water Footprint with increase affluence. Virtual Water is part of our unseen Water Footprint that needs to be reduced. Our young must be imbued in learning by listening and undertaking hands-on-real-life practical steps in measuring individual Water Footprint in schools and at home.

The every drop that comes from the drips of the taps is similar to leakages in water piping system. Such practice of collecting and/or eliminating leaks could be replicated in every educational institution or home or working place from the lowest level so that the true meaning of Every Drop Counts can be imbued for life. Together we can stop the drip and drop of every leak. When an individual, every home, every corporation as well as every country practises such water-saving programme daily, the amount of water preciously collected for proper use will certainly contribute to humanity. The youngsters and the educated must learn to contribute to the environment to secure a better tomorrow for the growing population on mother earth.

In moving towards Water Footprint sustainability development goals for the environment and human security, every individual and entity shall adopt nor a drop to drink till every drop counts. Every Drop of Water Footprint Counts for Humanity-Security, Equality and Equity.

\section{References}

[1]. The Rime of The Ancient Mariner by Samuel Taylor Coleridge https://genius.com/Samuel-taylor-coleridge-the-rime-of-the-ancient-marinerannotated

[2]. https://wholives.org/our-mission/mission/

[3]. Peace, dignity and equality on a healthy planet https://www.un.org/en/sections/issues-depth/water/ 
[4]. www.ourworldindata.org

[5]. Hanushek, Eric A.; Woessmann, Ludger. 2007. The Role of Education Quality for Economic Growth. Policy Research Working Paper; No. 4122. World Bank, Washington, DC. C) World Bank. https://openknowledge.worldbank.org/handle/10986/7154 License: CC BY 3.0 IGO.

[6]. Hoekstra, A. \& Hung, P. Virtual Water Trade: A Quantification of Virtual Water Flows between Nations in Relation to International Crop Trade Value of Water Research Report Series No. 11 (UNESCO-IHE Institute for Water Education, 2002);

[7]. Virtual water trade Proceedings of the International Expert Meeting on Virtual Water Trade Edited by A.Y. Hoekstra February 2003 Value of Water Research Report Series No. 12

[8]. Virtual water trade: Proceedings of the International Expert Meeting on Virtual Water Trade, IHE Delft, The Netherlands, 12-13 December 2002 A.Y. Hoekstra (editor) - February 2003

[9]. Tony Allen Virtual Water: Tackling the Treat to Our Planet's Most Precious Resource, Water International

[10]. https://www.theworldcounts.com/

[11]. Diffuse Pollution, Degraded Waters Emerging Policy Solutions https://www.oecd.org/environment/resources/Diffuse-Pollution-Degraded-WatersPolicy-Highlights

[12]. https://en.wikipedia.org/wiki/List of_countries by freshwater_withdrawal

[13]. https://www.globalcitizen.org/en/content/5-ways-waste-water-without-knowing/

[14]. United States Environmental Protection Agency, WaterSense https://www.epa.gov/watersense/fix-leak-week

[15]. Liew K.H., Sandra L.W.W. (2020) Minimum Level of Learning for Life: In Digitally Advancing Space and Pace. In: Leal Filho W., Azul A.M., Brandli L., Özuyar P.G., Wall T. (eds) Quality Education. Encyclopedia of the UN Sustainable Development Goals. Springer, Cham https://link.springer.com/referenceworkentry/10.1007\%2F978-3-319-95870$\underline{595}$

[16]. https://mothership.sg/2017/06/we-bet-like-80-of-singaporeans-waste-water-likethis/

[17]. https://www.channelnewsasia.com/news/singapore/singapore-world-water-daypub-water-wally-conservation-reservoir-11354350

[18]. https://www.booksandpeople.com.sg/are-you-wasting-water/

[19]. https://www.straitstimes.com/singapore/environment/saving-water-less-of-aconcern-for-younger-residents-study

[20]. https://lkyspp.nus.edu.sg/gia/article/why-water-conservation-efforts-often-comeup-dry. Max Roser and Esteban Ortiz-Ospina (2016) - "Literacy". Published online at OurWorldInData.org. Retrieved from: 'https://ourworldindata.org/literacy' 